\title{
FACTORIZATION OF SOME TRIANGULAR MATRIX FUNCTIONS AND ITS APPLICATIONS
}

\author{
Yu. I. Karlovich, J. Loreto-HernándeZ And I. M. SpitKovsKy
}

\begin{abstract}
We consider defined on the real line $\mathbb{R}$ matrix functions with monomial terms of the form $c e^{i \lambda x}$ on the main diagonal and one row, and with zero entries elsewhere. The factorability of such matrices is established and, moreover, the algorithm for their factorization is provided. In particular, formulas for the partial indices are derived, and conditions for them to all equal zero (that is, for the factorization to be canonical) are stated. These results are then used to obtain Fredholmness criteria for some convolution type equations on unions of intervals.
\end{abstract}

Mathematics subject classification (2010): Primary 47A68; Secondary 45E10, 47A53, 47B35. Keywords and phrases: Almost periodic factorization, geometric mean, convolution type equations, Fredholm operators.

\section{REFERENCES}

[1] M. A. Bastos, Yu. I. Karlovich, And A. F Dos SAntos, The invertibility of convolution type operators on a union of intervals and the corona theorem, Integral Equations and Operator Theory 42 (2002), 22-56.

[2] M. A. Bastos, Yu. I. Karlovich, And B. Silbermann, Toeplitz operators with symbols generated by slowly oscillating and semi-almost periodic matrix functions, Proc. London Math. Soc. (3) 89, 3 (2004), 697-737.

[3] A. S. Besicovitch, Almost periodic functions, Dover Publications Inc., New York, 1955.

[4] A. Böttcher AND YU. I. KARLovich, Carleson curves, Muckenhoupt weights, and Toeplitz operators, Birkhäuser Verlag, Basel and Boston, 1997.

[5] A. Böttcher, Yu. I. Karlovich, And I. M. Spitkovsky, Convolution operators and factorization of almost periodic matrix functions, Operator Theory: Advances and Applications, vol. 131, Birkhäuser Verlag, Basel and Boston, 2002.

[6] A. BRUdnyi, L. Rodman, AND I. M. SpitKovsky, Non-denseness of factorable matrix functions, J. Functional Analysis 261 (2011), 1969-1991.

[7] C. Corduneanu, Almost periodic functions, J. Wiley \& Sons, 1968.

[8] J. B. Garnett, Bounded analytic functions, Academic Press, New York, 1981.

[9] R. Hunt, B. Muckenhoupt, And R. Wheeden, Weighted norm inequalities for the conjugate function and Hilbert transform, Trans. Amer. Math. Soc. 176 (1973), 227-251.

[10] YU. I. KARLOVICH AND J. LORETO HERnÁnDEZ, Wiener-Hopf operators with semi-almost periodic matrix symbols on weighted Lebesgue spaces, Integral Equations and Operator Theory 62, 1 (2008), $85-128$.

[11] YU. I. KARLOVICH AND J. LORETO HeRnÁndEZ, Wiener-Hopf operators with slowly oscillating matrix symbols on weighted Lebesgue spaces, Integral Equations and Operator Theory 64, 2 (2009), 203-237.

[12] Yu. I. KARLOVICH AND J. LORETO HERnÁnDEZ, Wiener-Hopf operators with oscillating symbols on weighted Lebesgue spaces, Recent trends in Toeplitz and pseudodifferential operators, Operator Theory: Advances and Applications, vol. 210, Birkhäuser Verlag, Basel, 2010, pp. 123-145.

[13] YU. I. KARLOVICH AND J. LORETO HeRnÁndeZ, Convolution type operators with oscillating symbols on weighted Lebesgue spaces on a union of intervals, Mathematica 54 (77) (2012), no. Special Issue, 104-119. 
[14] YU. I. KARLOVICH AND I. M. SPITKOVSKY, Factorization of almost periodic matrix functions and (semi) Fredholmness of some convolution type equations, No. 4421-85 dep., VINITI, Moscow, 1985, in Russian.

[15] YU. I. Karlovich AND I. M. SPITKovsky, Factorization of almost periodic matrix-valued functions and the Noether theory for certain classes of equations of convolution type, Mathematics of the USSR, Izvestiya 34 (1990), 281-316.

[16] B. M. LEVITAN AND V. V. ZhiKov, Almost periodic functions and differential equations, Cambridge University Press, 1982.

[17] C. V. M. VAn Der Mee, L. Rodman, And I. M. Spitkovsky, Factorization of block triangular matrix functions with off diagonal binomials, Operator Theory: Advances and Applications 160 (2005), 423-437.

[18] C. V. M. van der Mee, L. Rodman, I. M. Spitkovsk y, and H. J. Woerdeman, Factorization of block triangular matrix functions in Wiener algebras on ordered abelian groups, Operator Theory: Advances and Applications 149 (2004), 441-465.

[19] S. C. POwER, Fredholm Toeplitz operators and slow oscillation, Canad. J. Math. 32, 5 (1980), 1058 1071.

[20] D. SARason, Toeplitz operators with semi-almost periodic symbols, Duke Math. J. 44, 2 (1977), 357-364.

[21] I. M. SPITKOVSKY, Factorization of several classes of semi-almost periodic matrix functions and applications to systems of convolution equations, Izvestiya VUZ., Mat. (1983), no. 4, 88-94 (in Russian), English translation in Soviet Math. - Iz. VUZ 27 (1983), 383-388. 